\title{
Aeróbios Mesófilos na Verificação da Eficiência do Tratamento Térmico em Salmouras Utilizadas no Preparo de Charque
}

\section{Mesophilic Aerobic Count for Determination of the Efficiency of the Heat Treatment Applied to the Brine Used for "Charque" Preparation}

\author{
Paulo Cesar Pavia' ${ }^{1}$ Luiz Antonio Trindade de Oliveira² , Robson Maia Franco²,
}

\begin{abstract}
Resumo
Visando a determinação da eficiência do tratamento térmico aplicado na recuperação de salmouras utilizadas no preparo de charque, foram estudadas 72 amostras (36 antes e 36 após a recuperação) adquiridas em uma indústria de conservas cárneas do Estado do Rio de Janeiro sob regime do Serviço de Inspeção Federal. As análises envolvidas neste estudo foram o crescimento e contagem de bactérias heterotróficas mesófilas aeróbias estritas e facultativas viáveis. Verificaram-se também os valores de temperatura das salmouras antes do processo de recuperação, a temperatura de fervura, o pH e as concentrações de sal antes e após o tratamento (sem novo reforço de sal). O tratamento térmico na recuperação das salmouras se mostrou eficiente e recomendada sob o ponto de vista microbiológico.
\end{abstract}

Palavras-chave: charque; salmoura; recuperação de salmouras; aeróbios mesófilos

\section{Introdução}

Denomina-se charque ao produto resultante do processamento da carne bovina desossada através de salga e dessecação, permitindo sua conservação em condições ambientais. O Regulamento da Inspeção Industrial e Sanitária de Produtos de Origem Animal - RIISPOA, em seu artigo 431 define esse produto da seguinte forma: "Entende-se por charque, sem qualquer outra especificação, a carne bovina salgada e dessecada" (Brasil 1980).

A salga úmida é a etapa do preparo do charque onde as mantas são mergulhadas em tanques contendo salmoura saturada que pode ser um dos elementos a colaborar com o aumento da microbiota do produto final. Visando a uma maior conservação da salmoura e evitar sua fermentação, ela é mantida à baixa temperatura (cerca de $15^{\circ} \mathrm{C}$ ).

Fagundes (1982) afirma que em muitas charqueadas a salmoura não é desprezada sendo periodicamente renovada ou recuperada (em função da deterioração dos componentes orgânicos) para minimizar os efeitos da fer- mentação e da multiplicação bacteriana com o propósito da já citada economia de sal. Dentre os métodos de recuperação utilizados, o mais comum e mais simples é o tratamento pelo calor (fervura) seguido de resfriamento e sedimentação (Pardi et al. 1994).

A salmoura esterilizada pela fervura é filtrada, resfriada em sistema próprio e recebe novo reforço de sal antes de retornar aos tanques de salmouragem*. Esse método tem a desvantagem de manter as proteínas solúveis a quente (Pardi 1961; Pardi et al. 1994). Assim, a prática de recuperação da salmoura empregada no fabrico de charque vem sendo abandonada nos últimos anos (Pardi 1961).

Oliveira (1977), em análise microbiológica do sal proveniente de Mossoró e Macau (RN) destinado à elaboração de charque, encontrou $100 \%$ de contaminação, com contagem de aeróbios mesófilos menor que $3 \times 10^{2}$ UFC/ g. Quanto ao isolamento e identificação de bactérias halófilas, $100 \%$ pertenciam à família Halobacteriaceae. Franco e Jurgensen (1984a), pesquisando enterococos em 40 amostras de charque a granel, concluíram que os enterococos podem ser considerados microrganismos indicadores presentes, pois resistiram à ação da salga e desidratação a que é submetida a carne durante o processamento tecnológico. Em outro trabalho, Franco e Jurgensen (1984b) analisaram 40 amostras de charque embaladas à vácuo, comercializadas em Niterói e São Gonçalo (RJ). Em todas foram detectados enterococos, sendo que as provas bioquímicas indicaram a presença da espécie Enterococcus faecalis. A média do NMP encontrado foi de 811 enterococos por grama da amostra.

Atualmente, muitos são os microrganismos utilizados como indicadores da qualidade higiênica de alimentos; uma das metodologias empregadas com este propósito é a contagem de bactérias heterotróficas mesófilas aeróbias estritas e facultativas viáveis. As bactérias heterotróficas são indicadoras da qualidade higiênico-santária dos alimentos, bem como da eficácia dos métodos e sistemas de limpeza e desinfecção de um estabelecimento industrial (Thatcher e Clark 1973b).

O presente trabalho teve como objetivo a avaliação

\footnotetext{
1 Universidade do Oeste Paulista (UNOESTE), Presidente Prudente, SP, Brasil

${ }^{2}$ Departamento de Tecnologia de Alimentos, Faculdade de Veterinária, Universidade Federal Fluminense, Rua Vital Brazil Filho 64, $24230-340$ Niterói, RJ, Brasil
} 
microbiológica da eficiência do tratamento térmico aplicado para recuperação de salmouras utilizadas no preparo do charque, mediante os resultados das contagens de bactérias heterotróficas mesófilas aeróbias estritas e facultativas viáveis.

\section{Material e Métodos}

As 72 amostras de salmouras utilizadas no preparo de charque ( 36 antes e 36 após a recuperação) foram adquiridas em uma indústria de conservas cárneas do Estado do Rio de Janeiro sob regime do Serviço de Inspeção Federal, sem que tivessem recebido novo reforço de sal. Cada amostra foi colhida assepticamente, após homogeneização no tanque de salmouragem, utilizandose individualmente conchas de cozinha industrial de alumínio e recipientes de vidro esterilizados, de volume aproximado de $250 \mathrm{ml}$. As amostras colhidas antes do tratamento térmico foram transportadas até o laboratório em recipiente isotérmico contendo gelo reciclável. Por sua vez, as amostras colhidas após o tratamento e remoção dos resíduos foram transportadas em temperatura ambiente.

Cada amostra, em condições de assepsia, foi homogeneizada, e retirada uma líquota de $25 \mathrm{ml}$, que foi transferida para um frasco contendo $225 \mathrm{ml}$ de solução salina peptonada a $0,1 \%$ (SSP $0,1 \%$ ) esterilizada (diluição $10^{-1}$ ). Em seguida, pipetou-se $1 \mathrm{ml}$ dessa diluição para um tubo contendo $9 \mathrm{ml}$ de SSP $0,1 \%$, obtendo-se a diluição $10^{-2}$ e repetiu-se o procedimento para obtenção das diluições $10^{-3}, 10^{-4}, 10^{-5}$ e $10^{-6}$.

A contagem de bactérias heterotróficas mesófilas aeróbias estritas e facultativas viáveis (Swanson et al. 1992) foi realizada a partir de cada uma das diluições selecionadas através de semeadura pour-plate em placas de Petri em duplicata, adicionando-se $15 \mathrm{ml}$ de ágar padrão para contagem (Merck 5463), fundido a $45^{\circ} \mathrm{C}$. Após a solidificação do ágar, as placas foram invertidas e incubadas a $35-37^{\circ} \mathrm{C}$ por $48 \mathrm{~h}$. Em seguida, foram selecionadas as placas que continham entre 25 e 250 unidades formadoras de colonias (UFCs), para que fossem realizadas as contagens.

As temperaturas das amostras de salmouras foram aferidas através de termômetro digital. As mensurações das temperaturas das amostras não tratadas pelo calor foram feitas nos tanques de salmouragem no momento da colheita; a das amostras tratadas pelo processo de reciclagem foram realizadas e registradas no exato instante da ebulição (fervura). Os tempos de duração dos tratamentos térmicos não foram estudados, pois esses cessavam no exato momento da ebulição das salmouras.

Os valores de $\mathrm{pH}$ das amostras de salmoura colhidas antes e após a reciclagem foram obtidos através da medição direta em potenciômetro (São Paulo 1985), conforme as orientações do seu manual de instruções e a técnica de determinação eletrométrica.

A concentração de sal em graus Baumé ( $\left.{ }^{\circ} B e ́\right)$ das salmouras foi obtida pela imersão e leitura do aerômetro de
Baumé em proveta contendo $90 \mathrm{ml}$ de amostra.

No presente trabalho foram utilizadas medidas de estatística descritiva, pois as características dos dados eram de boa compreensão através da expressão numérica e percentual simples. Utilizaram-se as seguintes medidas de tratamento estatístico: medidas de posição (média aritimética e mediana) e medidas de variabilidade (desvio padrão, coeficiente de variação e intervalo de confiança 95\%), segundo Fonseca e Martins (1982), visando a encontrar os valores mais prováveis das amostras dentro de intervalos considerados $(P<0,05)$.

Para auxílio nos cálculos, foi utilizado o programa de computador para estatística "In Stat", da Graph Pad Software Inc. (1983).

\section{Resultados}

As salmouras antes do tratamento térmico (recuperação) apresentavam-se turvas e de coloração marromavermelhadas. Após o tratamento, as mesmas estavam límpidas e com tonalidade amarelada.

Os resultados das contagens de bactérias heterotróficas mesófilas aeróbias estritas e facultativas viáveis das 36 amostras de salmouras não tratadas pela recuperação apresentaram mediana de $228,82 \times 10^{5}$. Observou-se crescimento microbiano em todas as amostras não tratadas. Por sua vez, as 36 amostras tratadas pelo calor (recuperação das salmouras) tiveram ausência de crescimento das bactérias pesquisadas (Fig. 1).

Os valores da concentração de sal das amostras não tratadas e tratadas tiveram como médias, respectivamente, $23,9^{\circ}$ Bé e $21,8^{\circ}$ Bé, enquanto que as médias dos valores de $\mathrm{pH}$ foram, 5,6 (não tratadas) e 5,5 (tratadas). Já os valores da temperatura antes da recuperação tiveram a média de $13,9^{\circ} \mathrm{C}$ e os da temperatura de fervura do processo de reciclagem das salmouras, $102,6^{\circ} \mathrm{C}$.

As análises estatísticas dos resultados são apresentadas nas Tabelas 1,2 e 3.

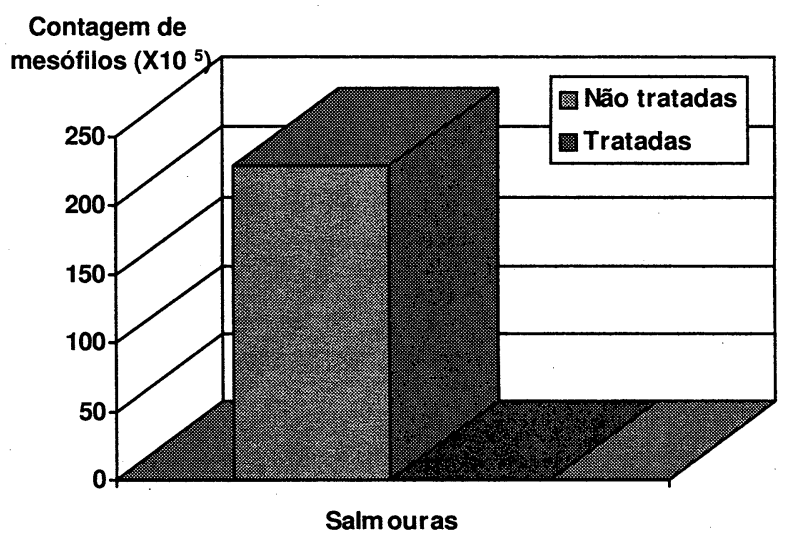

Comparação entre as medianas das contagens de bactérias heterotróficas mesófilas aeróbias estritas e facultativas viáveis (UFCs/ $\mathrm{ml}$ ). 
Tabela 1 - Comparação estatística entre os valores de pH encontrados nas amostras de salmoura antes e após a reciclagem

\begin{tabular}{lccccc}
\hline Amostras & $\begin{array}{c}\text { Média } \\
(\mathrm{pH})\end{array}$ & $\begin{array}{c}\text { Desvio } \\
\text { padrão }\end{array}$ & $\begin{array}{c}\text { C. de } \\
\text { variação }\end{array}$ & \multicolumn{2}{c}{$\begin{array}{c}\text { Intervalo de } \\
\text { confiança (95\%) }\end{array}$} \\
\cline { 5 - 6 } & & & & LI & LS \\
\hline Não tratadas & 5,60 & 0,14 & 2,50 & 5,58 & 5,67 \\
Tratadas & 5,50 & 0,21 & 3,82 & 5,40 & 5,54 \\
\hline
\end{tabular}

Tabela 2 - Comparação estatística entre os valores de temperatura das amostras de salmoura antes da reciclagem e das temperaturas de fervura das amostras recicladas

\begin{tabular}{lrrrrr}
\hline Amostras & $\begin{array}{c}\text { Média } \\
(\mathrm{pH})\end{array}$ & $\begin{array}{c}\text { Desvio } \\
\text { padrão }\end{array}$ & $\begin{array}{c}\text { C. de } \\
\text { variação }\end{array}$ & \multicolumn{2}{c}{$\begin{array}{c}\text { Intervalo de } \\
\text { confiança (95\%) }\end{array}$} \\
\cline { 5 - 6 } & & & & \multicolumn{1}{c}{ LI } & \multicolumn{1}{c}{ LS } \\
\hline Não tratadas & 13,90 & 2,17 & 15,61 & 13,26 & 14,73 \\
Tratadas & 102,60 & 1,24 & 1,21 & 102,18 & 103,02 \\
\hline
\end{tabular}

Tabela 3 - Comparação estatística entre os valores de concentração de sal das amostras de salmoura antes e após a reciclagem

\begin{tabular}{lcccc}
\hline Amostras & $\begin{array}{c}\text { Média } \\
\text { ('Bé) }\end{array}$ & $\begin{array}{c}\text { Desvio } \\
\text { padrão }\end{array}$ & $\begin{array}{c}\text { C. de } \\
\text { variação }\end{array}$ & $\begin{array}{c}\text { Intervalo de } \\
\text { confiança (95\%) }\end{array}$ \\
\cline { 3 - 5 } & & & LI & LS \\
\hline
\end{tabular}

Não tratadas $23,90 \quad 0,78 \quad 3,26 \quad 23,62 \quad 24,16$ Tratadas $\begin{array}{lllll}21,80 & 0,58 & 2,66 & 21,61 & 22,00\end{array}$

\section{Discussão}

Os reflexos que podem ser fornecidos pela contagem de bactérias heterotróficas mesófilas aeróbias estritas e facultativas viáveis de produtos alimentícios são: condições de manipulação, grau de frescor, estado de decomposição qualidade sanitária, condições de manutenção ou armazenamento (Thatcher e Clark 1973 a) e a existência de condições para a multiplicação dos possíveis germes patogênicos presentes, como certas espécies de Salmonella, Staphylococcus, Clostridium, Shigella e Bacillus (Banwart 1989a). As contagens de bactérias heterotróficas mesófilas aeróbias estritas e facultativas viáveis mostraram uma mediana de $228,82 \times 10^{5} \mathrm{UFCs} /$ $\mathrm{ml}$ nas amostras não tratadas pelo calor (não recuperadas). Esse valor está acima daqueles encontrados por Gutheil (1960) em salmouras de charque com uma a dez semanas de uso. As contagens de bactérias aeróbias encontradas nelo autor variavam entre $1,4 \times 10^{5} \mathrm{UFCs} / \mathrm{ml}$ e $62,5 \times 10^{5} \mathrm{UFCs} / \mathrm{ml}$. A amostra que apresentou este último valor estava em início de deterioração. $O$ autor propõe que a melhor indicação das condições da salmoura é a fornecida pelo potencial de oxidação-redução.

A presença das bactérias pesquisadas não está necessariamente ligada à veiculação da salmoura recuperada no charque pronto, fazendo com que a contamina- ção ocorra nas etapas tecnológicas sucessivas.

As temperaturas do processo de reciclagem das amostras (temperatura de fervura) verificadas estavam acima de $100^{\circ} \mathrm{C}$, com média de $102,6^{\circ} \mathrm{C}$. O tratamento térmico realizado foi $100 \%$ eficaz pois destruiu todos os microrganismos presentes. Banwart (1989b), Jay (1992) e Pardi et al. (1994) afirmam que isto se deve ao fato de as altas temperaturas inativarem enzimas e desnaturarem proteínas produzidas pelos germes.

Em relação ao tratamento da salmoura mencionado por Gutheil (1960), Pardi (1961), Fagundes (1982) e Pardi et al. (1994), as amostras deste trabalho, tratadas pela recuperação na indústria, resultaram em salmouras amareladas, com aspectos compatíveis às suas utilizações.

A temperatura média das amostras antes da reciclagem, ou seja, aquela em que a salmoura era mantida no processo de salga, foi de $13,9^{\circ} \mathrm{C}$ (em média). Este valor, considerando-se a bibliografia consultada, está dentro de um intervalo ideal.

Os valores de $\mathrm{pH}$ encontrados nas amostras não recicladas (média de 5,6), decorrentes da adição de ácido lático, mostraram que as mesmas se encontravam na faixa ácida. Esses valores estão em concordância com Picchi e Cia (1981), Fagundes (1982) e Picchi (1991), já que o procedimento visa a conservação por um período de tempo maior, evitando fermentações indesejáveis e a multiplicação excessiva de microroganismos, principalmente patogênicos. Após o tratamento térmico de recuperação, a faixa de $\mathrm{pH}$ das amostras foi de, em média, 5,5 . Gutheil (1960) menciona que o pH inicial da salmoura é de, aproximadamente, 7,0 e que um tamponamento pela adição de proteínas da carne ocorre com o seu uso. 0 autor relata ainda que a salmoura sã, já utilizada na salga de carne, se apresenta ligeiramente ácida, com pH variando entre 6,0 e 6,6 e que o valor de pH nem sempre é uma indicação do estado da salmoura. No estudo realizado com salmoura utilizada na salmouragem de sardinha, Carmo (1991) encontrou pH médio de 5,5 e afirma que este valor provavelmente seja decorrente do resíduo de pescado e elementos modificados de sua composição iônica. No presente estudo, a média dos valores de $\mathrm{pH}$ estava na faixa ácida em razão da adição de ácidos orgânicos (ácido lático), porém, os resultados das análises microbiológicas mostraram que o uso de ácido lático na salmoura não atingiu seu propósito.

A concentração salina média das amostras analisadas antes e após a reciclagem foram, respectivamente, $23,9^{\circ}$ Bé e $21,8^{\circ}$ Bé. As amostras antes do tratamento térmico, de acordo com Pardi (1961), Picchi e Cia (1981), Picchi (1991) e Pardi et al. (1994) se encontravam dentro da faixa de concentração ideal (23,5 a $24^{\circ}$ Bé). Mesmo assim, foi necessário o reforço de sal após o tratamento térmico para reconstituição da densidade da salmoura.

As análises estatísticas dos resultados mostraram que não ocorreram alterações significativas das concentrações de sal e dos valores de $\mathrm{pH}$ antes e após o processo de 
recuperação $(P<0,05)$, não havendo interferência do tratamento térmico das amostras.

O charque, apesar de ser um produto cárneo ligado à própria história da cultura brasileira e enraizado nos hábitos alimentares do povo, tem sido objeto de poucas pesquisas (Shimokomaki et al. 1987). Nesta pesquisa pudemos constatar um desinteresse semelhante em relação ao seu processamento tecnológico, principalmente sobre as salmouras utilizadas na etapa de salgação das carnes. Esta constatação é comprovada pelos pouquíssimos trabalhos disponíveis com enfoque voltado às salmouras. Além disso, a inexistência de padrões microbiológicos oficiais para a destinada ao preparo do charque não permitiu uma meIhor comparação e avaliação dos resultados obtidos. Observou-se neste trabalho que, o tratamento pelo calor realizado em equipamentos e locais apropriados remove as impurezas coaguladas sobrenadantes e/ou sedimentadas da salmoura, na sua maioria formadas por proteínas solúveis extraídas da carne, para que, posteriormente, seja resfriada, reconstituída na sua concentração salina e reutilizada. Também foi observado que a conveniência do tratamento de recuperação da salmoura está ligada à diminuição de efluentes industriais para estações de tratamento de resíduos e à possibilidade de aproveitamento dos resíduos coagulados (material proteico) pela graxaria.

\section{Abstract}

\section{Mesophilic aerobic count for determination of the ef- ficiency of the heat treatment applied to the brine used for "charque" preparation}

Seventy-two samples of brine used for preparing "charque" were studied in order to determine the efficiency of heat treatment applied to its recuperation. These samples ( 36 before and 36 after recuperation) came from an industry of the State of Rio de Janeiro which has Federal Inspection Service. The analysis used for this study was the enumeration of mesophilic aerobic bacteria by colonies counting. The temperature of brine before the recuperation process, the boiling point and the values of $\mathrm{pH}$ and the salt concentration before and after the treatment (without new salt reinforcement) were studied. Based on the results of this study, the utilization of heat treatment for recuperation of brine is efficient and recomended under microbiological point of view.

\section{Key words: charque; brine; brine recovery; mesophilic aerobic bacteria}

\section{Referências bibliográficas}

Banwart G 1989a. Factors that affect microbial growth in food, p. 101-163. In Basic Food Microbiology, New York.

Banwart G 1989b. Control of microrganisms by destruction, p. 651-723. In Basic Food Microbiology, New York.

Brasil 1980. Ministério da Agricultura. Secretaria Nacional de
Defesa Agropecuária, SNDA/SIPA. Regulamento da Inspeção Industrial e Sanitária de Produtos de Origem Animal RIISPOA. Aprovado pelo Decreto № 30.691 de 29/03/52, alterado pelo Decreto $N^{\circ} 1255$ de 25/06/62. Brasília, DF, $166 \mathrm{pp}$.

Carmo RP 1991. Controle de Qualidade da Salmoura Utilizada na Produção de Conserva de Pescado. Dissertação de Mestrado, Faculdade de Veterinária; Universidade Federal Fluminense, Niterói, 84 pp.

Fagundes SG 1982. Avaliação de Nova Técnica na Prodúção de Charque. Dissertação de Mestrado, Faculdade de Veterinária, IJniversidade Federal Fluminense, Niterói, 63 pp.

Franco RM, Jurgensen CA 1984a. Enterococos em charque a granel. Higiene Alimentar 3: 119-120.

Franco RM, Jurgensen CA 1984b. Enterococos em charque embalado à vácuo. Higiene Alimentar 3: 119-120.

Gutheil NC 1960. Contribuição ao estudo de salmouras na elaboração de charque, p. 1-20. Anais da Associação Brasileira de Química.

Holt JG, Krieg NR, Sneath PHA et al. 1994. Bergey's Manual of Determinative Bacteriology. Wiliams \& Wilkins, Baltimore, $787 p p$.

Jay JM 1992. Food preservation and some properties of psychotrophs, termophiles, radiation-resistant and lactic acid bacteria. Chapter 14: High-temperature food preservation and characteristics of thermophilic microorganisms, p. 335355. In Modern Food Microbiology, 4 ed., Chapman \& Hall, New York.

Oliveira LAT 1977. Análise Microbiológica do Sal (NaCl) Empregado na Elaboração do Charque. Dissertação de Mestrado em Medicina Veterinária, Universidade Federal Fluminense, Niterói.

Pardi MC 1961. Elaboração do Charque no Brasil: Conveniência de Novos Rumos em Sua Tecnologia. Tese (Concurso de Professor Catedrático da 16 a $^{\text {a }}$ Cadeira - Tecnologia de Produtos de Origem Animal), Faculdade Fluminense de Medicina Veterinária, Niterói, 44 pp.

Pardi MC, Santos IF, Souza ER et al. 1994. Processamento tecnológico da carne, p. 719-986. In Ciência, Higiene e Tecnologia da Carne. UFG, Goiânia.

Picchi V 1991. Preparação do charque. Rev Nac da Carne16: 37-45.

Picchi V, Cia G 1981. Fabricação do charque. Boletim Técnico do Centro de Tecnologia da Carne do ITAL (Instituto de Tecnologia de Alimentos) 5:.11-30.

São Paulo 1985. Secretaria de Estado da Saúde. Normas Analíticas do Instituto Adolfo Lutz. 3 ed. IAL, São Paulo, 553 pp.

Shimokomaki M, Franco BDGM, Carvalho JRBC 1987. Charque e produtos afins: tecnologia e conservação - uma revisão. Boletim da Sociedade Brasileira de Ciência e Tecnologia de Alimentos 21: 25-35.

Swanson KMJ, Busta FF, Peterson EH et al. 1992. Colony Count Methods, p. 75-95. In Compendium of Methods for the Microbial Examination of Foods, 2 ed., APHA, Washington.

Thatcher FS, Clark DS 1973a. Microorganismos patogenos presentes en los alimentos, p. 1-56. In Analisis Microbiologico de los Alimentos. Acribia, Zaragoza.

Thatcher FS, Clark DS 1973b. Selección de métodos para el analisis microbiológico de los alimentos, p. 57-178. In Analisis Microbiologico de los Alimentos. Acribia, Zaragoza. 